\title{
SOUZA, Ronaldes de Melo e. $O$ romance tragicômico de Machado de Assis. Rio de Janeiro: Ed. UERJ, 2006.
}

Marcos Rogério Cordeiro Universidade Federal de Minas Gerais

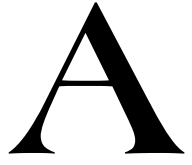

crítica literária brasileira e estrangeira se acostumou a repetir que a obra de Machado de Assis pode ser dividida em duas fases: a primeira (até 1881, data de publicação de Memórias póstumas de Brás Cubas) se caracterizaria por adotar formalmente a estética romântica, apresentando menor tensão psicológica, narrativa mais linear e narradores e personagens mais acanhados, enquanto a segunda, que inaugura o realismo brasileiro, apresentaria maior densidade dramática, narrativa digressiva e reflexiva e narradores e personagens mais desenvoltos. Podemos encontrar poucos exemplos que defendem o contrário, argumentando que existe sim uma linha de continuidade entre todos e cada um dos romances escritos por Machado, resultado de uma certa acumulação de consciência de estilo.
Menos ainda os estudos que fazem isso de maneira convincente, analisando os livros isoladamente, buscando e identificando algum aspecto importante que reapareça nos demais de maneira alterada ou diferente, inter-relacionando, assim, cada obra em relação com o conjunto. Lembro aqui de alguns que procuram fazer esse exercício de análise, comparação e relação: The craft of an absolute winner: characterizations and narratology in the novels of Machado de Assis (1983), de Maria Luíza Nunes, que analisa pelo menos dois aspectos importantes tentando mostrar como eles se constituem como linhas de força de toda ficção machadiana: o desenvolvimento de personagens complexos construídos mediante a estruturação de personalidades ambíguas, contraditórias e performáticas e o recurso de variação de pontos de vista que 
permite que o narrador estabeleça com o leitor uma relação crítica diante dos eventos narrados; e Os leitores de Machado de Assis (2004), de Hélio Seixas Guimarães, que mostra como - do primeiro ao último romance - Machado de Assis alterou e inovou os modelos de recepção literária no Brasil oitocentista na medida em que subverteu a presença e a função do leitor implícito, que passa a questionar cada lance do enredo, ajudando, assim, o leitor real a compreender os detalhes da narração de modo crítico e reflexivo.

A esses dois livros inteligentes vem somar O romance tragicômico de Machado de Assis, de Ronaldes de Melo e Souza, professor de Literatura Brasileira da Universidade Federal do Rio de Janeiro. O estudo é dividido em duas partes. $\mathrm{Na}$ primeira parte ("A poética do romance machadiano") encontramos três capítulos que procuram identificar um método de composição rigoroso, tão comum nos escritos de Machado de Assis: um capítulo analisa as metamorfoses pelas quais passa o narrador machadiano, desembaraçando-se de si mesmo e multiplicando exponencialmente as possibilidades de narração e reflexão sobre a narração; o outro capítulo investiga a construção da narrativa a partir da ironia, entendida como um dispo- sitivo formal e não como um tropo literário - a ironia formal consiste na elaboração de estruturas refletoras que permitem que cada personagem seja compreendido como um duplo, assim como o narrador e também o leitor; o terceiro, especifica melhor a noção de tragicômico, demonstrando de que modo essa noção se desenvolveu como desdobramento da ironia formal.

As conclusões a que o crítico chega são categóricas e reveladoras e mostram que os artifícios narrativos empregados por Machado de Assis estão baseados em um método de composição preciso e precioso: "o que caracteriza o estilo machadiano é o multiperspectivismo narrativo, formalmente configurado na adoção sucessiva e alternada de múltiplos pontos de vista." (p. 20) Esse estilo possui dois lados que se completam: (a) ele revela o universo da narração como um complexo meio de reflexão sobre o mundo e o ser, e, ao mesmo tempo, (b) demonstra como o mundo e o ser se constituem como forças ordenadoras do universo da narração: "A ciência do narrador machadiano se manifesta na consciência de que a realidade jamais é conhecida em si mesma", pois, "o real não é meramente dado, mas sempre construído." (p. 24) Compreende-se que o alcance das 
reflexões na ficção machadiana é filosófico, mas sua gênese, sua organização formal e seu desenvolvimento são eminentemente estéticos: "Postula-se que a literatura, além de representar acontecimentos, tem de ser uma forma privilegiada de conhecimento." (p. 38)

Aliado a tudo isso, chama atenção a maneira como o crítico analisa a obra e o pensamento de Machado de Assis e os compara com os de Platão, Plauto, Dionísio, Aristófanes, Luciano, Erasmo, Sterne, Schlegel, Schelling, Victor Hugo, Cervantes, Goethe, Diderot, etc., perfazendo assim um arco amplo, uma rede entrecruzada por relações e formas que revela a existência de uma tradição superior e pouco evidente, formada acima de qualquer outra que não seja reflexiva e estética ao mesmo tempo.

No vasto domínio da lite-ratura ocidental, o romancista brasileiro sobressai como um dos maiores ficcionistas de todos os tempos, sobretudo porque a forma dramática de seu romance descerra o amplo horizonte cognitivo, em que possível se torna reconhecer que o real se apresenta como uma força dinâmica de gestação de sentidos que se formam e se transfor-mam em consonância com as formações discursivas dos sujeitos que protagonizam os papéis culturalmente disponíveis no mundo histórico social. (p. 11)

Partindo desses pressupostos críticos - cuja inspiração se encontra na hermenêutica filosófica - o professor Ronaldes empreende, na segunda parte ("O romance tragicômico machadiano"), uma análise dos romances de Machado de Assis, e vai, aos poucos, revelando afinidades formais surpreendentes entre eles: segundo o crítico, a cada livro, Machado variava, adensava e refletia os artifícios estéticos que usava e a visão de mundo que os explicava e exprimia. Vejamos como isso é desenvolvido passo a passo.

Em Ressurreição (1872), o narrador adquire um estatuto interpretativo, que o impulsiona e o permite interromper a narrativa e refletir sobre ela juntamente com o leitor implícito. (p. 73-74) A duplicidade estrutural a que o narrador se encontra submetido também pode ser observada nos personagens, tornando mais complexo o processo narrativo de mediação e meditação. (p. 75) Com isso, Machado amplia e diversifica as instâncias dramáticas do romance, pois ação e reflexão se encontram articuladas numa fatura ficcional única. Essa dualidade reaparece no romance seguinte, $A$ mão e a luva (1874), mas agora, além de desenvolver mais e melhor suas conseqüências funcionais no narrador e nos personagens, a 
duplicidade se converte em ironia. (p. 36) A partir da forma irônica, que desenvolve a dupla função de representação dos eventos narrados e reflexão sobre eles, Machado empreende uma espécie de desconstrução da estética romântica, seja através do narrador ou de Estevão, o jovem enamorado do livro.

Concentrando sua análise na gênese e no desenvolvimento das estruturas formais da ficção, o crítico encontra uma linha de continuidade entre os dois romances e desenvolve uma análise do Romantismo em consonância com o próprio Machado de Assis, ou seja, ele usa Machado para desmontar a tese sobre a fase romântica de Machado. Neste caso, a conhecida fórmula que divide a obra do grande escritor brasileiro em duas fases começa a ser desmontada por partes.

Essas características reaparecem debulhando novas situações dramáticas, existenciais e históricas nos dois romances seguintes, Helena (1876) e Iaiá Garcia (1878), aperfeiçoando e aprofundando o alcance da dualidade estrutural da ficção machadiana: ação e reflexão. Com isso, de maneira gradual e segura, Machado "substitui a narração progressiva de eventos consecutivos pela encenação do drama de caracteres". (p. 102)

Amadurecida essa forma do romance (o crítico adverte que existem diversas formas, p. 25-26), Machado inicia um projeto de desconstrução do realismo formal: Memórias póstumas de Brás Cubas (1881) rompe com praticamente todas as convenções da verossimilhança realista, tanto na ação como na representação. A partir daí, inicia-se uma análise de Quincas Borba (1892) que dota o romance de uma complexidade interessante: toda a narração passa por um processo de averiguação metanarrativo, mediando formas de dramatização dos eventos e de reflexão sobre eles. Neste aspecto, Quincas Borba e Memória póstumas de Brás Cubas apresentam homologias formais decisivas: "A invenção narrativa do defunto autor e a encenação do drama tragicômico do filósofo humanitista mutuamente se clarificam". (p. 124) Esse resultado é sinal do domínio que Machado tinha sobre o seu universo criado: o crítico compara a primeira e a segunda versões do livro e mostra como o romancista intensificou os conflitos dos personagens (consigo mesmos e entre si) e entre eles e o narrador, complexificando ainda mais as estruturas formais que organizam a ficção. Em Dom casmurro (1890), essa tensão adquire contornos trágicos na personalidade de Bento Santiago, o narrador mais shakespereano de Machado de Assis. Segundo a análise, Bentinho 
é uma espécie de desdobramento introspectivo de Brás Cubas. (p. 139) Mais: como desdobramento da duplicidade dramática que vinha sendo utilizada desde o primeiro romance (que, penso, também pode ser encontrada nos contos, nas crônicas e nos ensaios críticos) encontramos em Dom casmurro um dispositivo sofisticado utilizado na elaboração do enredo romanesco: "O narrador escreve dois textos. Um enfatiza a paranóia de Bento Santiago, e o outro denuncia o adultério de Capitu. O entrecruzamento dos textos contraditórios desencadeia a proliferação indefinida de ambivalências irredutíveis." (p. 147)

Os dois últimos romances, Esaú e Jacó (1904) e Memorial de Aires (1908), possuem um mesmo e único narrador, que, no entanto, se comporta de maneira duplicada, desempenhando a sutil e ambígua função de narrador-refletor. "Notase que o narrador ironicamente se desdobra na primeira e na terceira pessoa." (p. 160) Comparando a desenvoltura de Aires em um e outro livro, vemos que em ambos o personagem-narrador dramatiza a si mesmo ao mesmo tempo em que dramatiza a personalidade dos personagens.

Depois que o leitor percorre todo o livro do professor Ronaldes de Melo e Souza, fica com uma impressão mais fresca a respeito da obra de Machado de Assis, sente a força de seu estilo e é educado nas nuanças de suas variações. Também fica com a noção mais coesa do conjunto:

De Ressurreição ao Memorial de Aires, a forma genuína do romance machadiano consiste em submeter a uma trama de ações logicamente concatenadas ao drama das paixões vivenciadas pelos personagens e ao escrutínio crítico das reflexões do narrador. (p. 173)

Algumas palavras ainda devem ser ditas para esclarecer melhor o ponto de partida e o de chegada desse novo estudo sobre Machado de Assis. A respeito do seu método de análise e interpretação, observamos que o crítico parte de uma atitude crítica hermenêutica, lendo o texto cerradamente, acompanhando o desenvolvimento da narrativa, buscando relacionar o sentido à forma e vê-los como resultados de uma disciplina de escrita tipicamente machadiana. Para desenvolver sua tese principal ("elucidação da estrutura conjuntiva e coesa da forma dramática e da mundividência tragicômica", p. 9) e as derivadas (a respeito do narrador, da narrativa e dos personagens), o crítico parte do próprio Machado, construindo assim um círculo hermenêutico de auto-elucidação 
do sentido do texto e revelando como um gênio da literatura domina o seu próprio processo de criação. Além disso, nota-se que sua análise toma a obra de Machado como a verdadeira mediadora das possibilidades de sua compreensão: trata-se de um estudo focado em problemas estéticos, mas que se volta para interesses externos aos romances (filosofia da linguagem, da consciência, da história, dos gêneros), não para estabelecer relações, mas para considerar esses dados externos parte integrante da economia interna da ficção.

Sobre o método de trabalho, é visível a leitura atenta de diversos estudiosos da obra de Machado (o professor cita muitos deles, compara-os, refuta-os ou os incorpora às suas idéias) apresentando assim um vasto painel da fortuna crítica do escritor. Não obstante isso, o livro apresenta novidades na maneira de interpretar a obra machadiana. Acredito que isso se deve muito à formação crítica do autor do estudo: mesmo uma leitura rápida das referências bibliográficas revela o uso sistemático de uma bibliografia incomum, que gira em torno de temas e problemas como a ironia formal e a dramatização narrativa, o estatuto do narrador e a composição complexa dos personagens, os efeitos da poiésis no processo de construção de uma visão de mundo e as visões de mundo apresentadas como efeito da poiésis, etc. Poucos desses autores são conhecidos da maior parte daqueles que estudam literatura no Brasil. Por isso, temas e problemas já estudados pela crítica são reanalisados, adquirem um sentido novo e são desdobrados e relacionados a outros temas e problemas.

Ao contrário do que possa parecer para quem ainda tem uma visão superficial e doutrinada sobre Machado de Assis às vésperas de completarmos cem anos de sua morte, os estudos literários começam a dar sinais de uma boa renovação das teorias e dos métodos que auxiliam o trabalho de interpretação e crítica, principalmente diante da obra de um escritor com rara capacidade de tornar complexo o simples e simples o complexo isso se o objetivo for mesmo a compreensão desimpedida de uma concepção de mundo ficcional, tal como aquele que está em questão desenvolveu. 